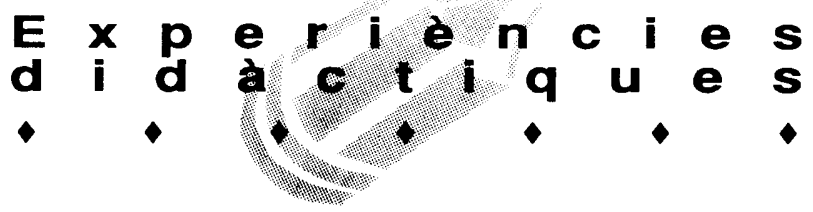

\section{UNA PROPOSTA DE TREBALL DE LÈXIC A L'ESCOLA}

\author{
Cecili Garriga Escribano. Professor de Llengua Espanyola a l'Ensenyament de Mestres
}

Els programes oficials del Departament d'Ensenyament $(1990,40)$ recullen, en l'apartat de «Fets, conceptes i sistemes conceptuals", en el segon bloc dedicat al "Treball sistemàtic de llengua", una part dedicada al "Lèxic". I en els continguts consigna els següents:

- Relacions entre mots per la seva forma.

- Relacions entre mots pel significat. fica:

Més endavant, als "Objectius terminals", especisignificat.

17. Identificar les relacions dels mots pel seu

- Polisèmia.

- Sinonímia i antonímia.

- Sentits propis i figurats.

- Comparació.

- Lexicalitzacio: modismes, locucions ifrases fetes.

Un tractament molt semblant s'atorgava a aquest aspecte en els "Marcs referencials" que es van donar a conèixer dins el "Programa experimental de Reforma Educativa" (Coromina, 1988, 32), on es parlava, per exemple, de la diferència entre polisèmia i homonímia ide la formació de camps lèxics i semàntics. Igualment als programes vigents a la resta de l'Estat (Gómez, 1989, 147).

Tanmateix, les propostes didàctiques per treballar aquesta qüestió solen ser bastant pobres, i no passen dels tradicionals exercicis sobre textos escrits i l'ús monòton del diccionari. Seguidament es presentarà una experiència basada en la utilització de la lletra d'una cançó d'un grup de música modern, que servirà per il.lustrar tots aquests fenòmens i treballar-los a la classe de llengua castellana.

\section{Fonamentació teórica}

L'aplicació dels mètodes estructurals a l'estudi del lèxic ha estat la qüestió primordial de la semàntica en l'afany per posar-se a l'alçada d'altres disciplines lingüístiques, com la fonologia o la morfologia, que s'identificaven amb la definició saussuriana de "llengua" com a sistema tancat on tots els elements es defineixen enuna relació d'oposició amb la resta. Es tractava d'utilitzar els mateixos mètodes que l'Escola de Praga aplicava a la fonologia, i arribar a descompondre el significat en trets elementals i esbrinar-ne el funcionament. No és aquest el lloc idoni per donar compte de la trajectória que ha seguit la semàntica des d'aleshores.'

Sí que cal dir, però, que a l'escepticisme d'alguns lingüistes ${ }^{2}$, s'oposen, entre d'altres, els treballs de Coseriu $(1972,11-86)$ que reconeix que el lèxic pot ser el domini menys estructurat de la llengua, però que pot rebre un tractament estructural. Per això cal reprendre el concepte de "camp lèxic", que aquest autor defineix com "un paradigma léxico continuo entre diferentes unidades dadas en lengua como palabras y que se oponen de manera inmediata unas a otras, por medio de rasgos distintivos minimos" ${ }^{3} ;$ els trets mínims són els semes. El camp lèxic pot facilitar l'adquisició del vocabulari, perquè ajuda a establir relacions metòdiques entre significats pròxims, que contribuiran a fixar-lo i usar-lo activament (Battaner, 1985, 200).

Una vegada establerta la noció de camp en la semàntica, quan el vocabulari ja es troba organitzat i estructurat, és quan es fa oportú observar quines relacions manté cada signe lingüístic envers els altres que es troben en la mateixa esfera. Per fer-ho es pot partir de la concepció de signe lingüistic que dóna Saussure (1916, 86): entitat psiquica de dues cares: concepte i imatge acústica, significat i significant respectivament. Les relacions entre els dos components del signe lingüístic donen lloc als fenòmens de la polisèmia i l'homonímia, la sinonímia, l'antonímia i els canvis de significat que generen la diferència entre sentits propis i figurats.

* Un significant i més d'un significat. Dins d'aquest grup es troben la polisèmia i l'homonimia. És el receptor qui resol els problemes d'interpretació del missatge que aquesta situació pot produir. La dificultat es troba a l'hora de diferenciar aquests dos fenòmens ${ }^{4}$. Des del punt de vista diacrònic, sembla que a l'homonímia s'arriba per mitjà d'un procés de confluència fònica, mentre que la polisèmia es produeix per un procés de diversificació semàntica -adquisició de noves accepcions sense perdre la primitiva - 5 . Peró situant la qüestió en sincronia, la diferència no sembla tan clara. Es parla d'homonímia en aquells casos en què no hi ha cap sema en comú entre els dos significats, i de polisèmia quan els significats en comparteixen algun. El que és cert és que el parlant veu com a homonimia molts casos que etimológicamente són polisèmics, perquè n'ha perdut la noció de relació entre 


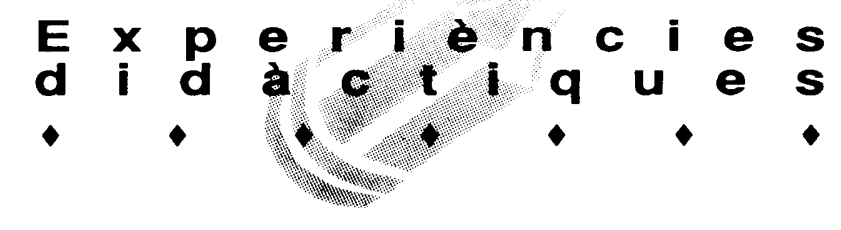

llurs significats. És evident que per a un filòleg, que coneix l'etimologia de les paraules, hi ha més polisèmies que per a un parlant normal 6 .

* Un significat i més d'un significant. El cas per excel.lència és el de la sinonímia. l el primer problema és definir quan dues unitats lèxiques són sinònimes. Si es parteix de l'anàlisi componencial, s'haurà de fixar com a condició que totes dues unitats presentin els mateixos trets semàntics, i siguin equivalents en tots el contextos. Davant aquestes exigències, l'opinió dels lingüistes és que la sinonímia total no existeix, o és gairebé impossible ${ }^{7}$. El que fa Lyons $(1968,592)$ és establir diferents tipus de sinonímia, perquè proposa una diferència entre el que Ullmann anomena sentit o significat cognitiu i emotiu. D'aquesta manera parlarà de sinonímia completa - quan l'equivalència entre dos signes és de sentit cognitiu i emotiu—, i de sinonímia total —quan l'equivalència és només de sentit cognitiu. Gairebé sempre que es parla de sinònims, s'amaguen variants dialectals, sociolingüistiques, o suposen fenòmens d'hiperonímia 0 hiponímia: «la relación que se establece entre un lexema más específico o subordinado y otro más general o superordinado"[Lyons (1977, 273-277)], com passa entre els lexemes 'vaca':'animal', 'llimona':'fruita', 'honradesa':'virtut'. Els diccionaris de sinònims donen equivalències d'aquest tipus en la majoria dels casos, i és un dels sistemes que s'usen en la definició.

Un cas a part és el de l'antonímia. Tradicionalment s'entenia com antonímia les parules de significat "contrari». Amb l'anàlisi componencial de la semàntica estructural, es veu clarament la inconsistència d'aquest principi, ja que cada lexema es pot oposar per diversos semes a d'altres lexemes. Serveixi l'exemple de Cabré i Rigau $(1985,171)$.

dona [+ humà] / vaca [- humà]

[+ femella] / home [-femella]

[+ adult] / nena [- adult]

Es pot observar com 'dona' estableix relacions d'oposició amb 'vaca', 'home' i 'nena'. Per tant, l'oposició semàntica no és homogènia. Es poden trobar casos, classificats com a antonímia, que són de "complementarietat semàntica": mascle/femella, mentida/ veritat, etc., i d'altres tipus de rel.lacions. La veritable antonímia sembla que s'ha de buscar en relacions polars o graduals: amic/enemic, mai/sempre, etc. Però tornant al concepte tradicional d'antonímia (contrari) -és el que pot ajudar l'alumne a organitzar el seu univers lingüistic-. sembla evident que el grau de polisèmia d'una paraula és inversament proporcional a la possibilitat d'establir antonímies totals, ja que cada accepció pot desenvolupar la seva oposició antonímica ${ }^{8}$.

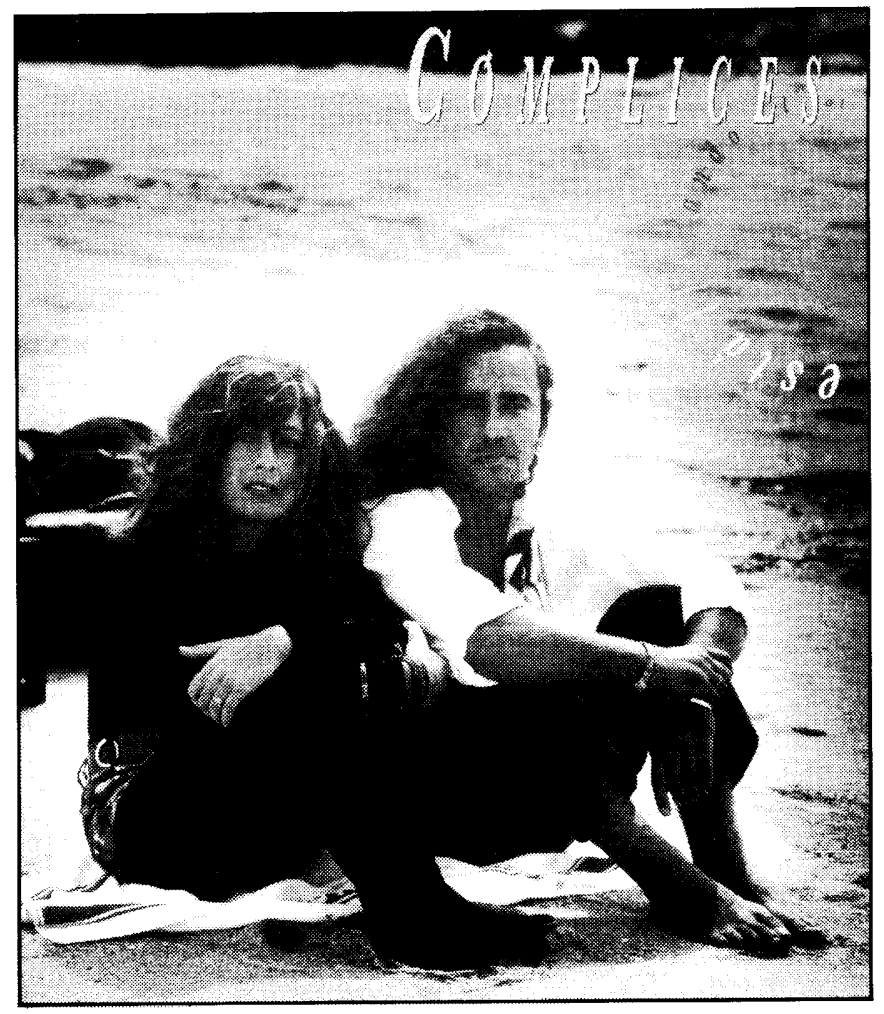

Per últim, s'estableix, de vegades (especialment als diccionaris ${ }^{9}$ ), la contraposició entre els sentits propis ifigurats d'un mot. És un cas que podria incloure's dins del grup de la polisèmia i l'homonimia, ja que un significant admet un sentit diferent al propi a partir d'una relació de significats. En el fons es tracta d'usos metafòrics ${ }^{10}$. I així els classifica Ullmann (1965): metàfores antropomòriques (pulmons de la ciutat, manetes del rellotge), animals (ser un ruc, o una rata), sinestèsiques (veu clara, caràcter agre, color estrident), etc. Caldria afegir les metonímies $\mathrm{i}$ les sinècdoques com a generadores de sentits figurats (he menjat dos plats, he begut un conyac, etc).

\section{El treball pràctic}

L'experiència que es presenta es fa a partir d'una cançó en castellà, del grup musical "Cómplices", que al seu últim disc titulat “Está llorando el sol» (BMG, 1991), inclou el tema "Verdad que sería estupendo", compost per Teo Cardalda i J.M. Montes, segon senzill del grup, que es va fer molt popular al primer trimestre d'aquest any. El tema és especialment adequat per a aquest treball, com a continuació es podrà veure per la lletra: 


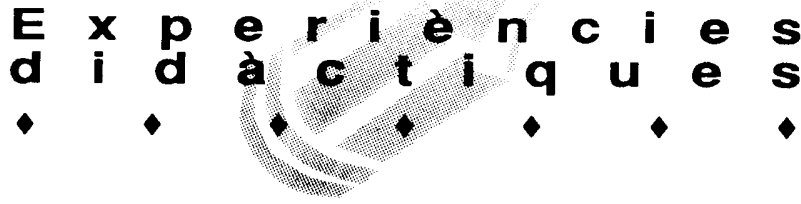

\section{VERGAD QUE SERIA ESTUPENDO}

Verdad gue seria estupendo

908 as espadas to eran un pato de la barala que el escudo una moneda portuguesa

y un lanque una arra grande de cerveza.

Verdad que serla estupendo

que las bases fueran el lado de un trianoulo. que las escuadras solo reglas de diseno Y $10 s$ gatillos gatos pequenos:

que apuntar ruera so plarte fa labla a Manolito que disparar darle una patada a un balon. yque los spersing w lieran esa marca de rotulador con los que tu slempre phtas mil corazon

Verdad que seria estupendo que las bombas tueran globos de chicle. que las sirenas fueran peces con cuerpo de mujer Ylas granedas una clase de fruta

Oue alarma fuera tna grupo we rock and rofl, y que la pónora tuera para hacer fuegos artificlates. y que los apersing tueran esa marca de rolulador con los que w siempre onias mi corazon. con os que yo slempre olino tu corazon

Y no oxistlera mas anna en el mundo Yno existlera más ama en el mundo. mas quo el w mima a andatuz

Yeroad que serra estupendo?

Abans de començar, cal dir que prescindeixo d'altres possibilitats de treball d'aquest material, que les té, i em centro en l'aspecte semàntic; tampoc no tractaré la presentació i introducció del material a la clase.

La cançó té una estructura molt senzilla: cinc estrofes de quatre versos (perquè la cinquena repeteix l'últim vers). En la primera, segona i quarta es comença amb la pregunta que serveix de títol, i després una sèrie de subordinades substantives introduïdes per "que". Però no és la sintaxi l'objecte d'aquest comentari, sinó la semàntica. A cada vers es contraposen dos conceptes:

Sería estupendo que " $A$ " fuera " $B$ "

On " $A$ " és un significant que pot tenir més d'un significat, $i$ un d'ells, el primer, pertany al camp lèxic que podriem anomenar de la "guerra", o de les "armes", etc.; després tornarem sobre això. I "B" és un significant que manté una relació de sinonímia amb una de les accepcions de “A», precisament la no bèl.lica. Vegem-ho:

$\begin{array}{ll}\text { espada } & \text { 'arma' } \\ & \text { 'naipe' } \longrightarrow \text { palo de la baraja } \\ \text { granada } & \text { 'arma' } \\ & \text { 'fruta' } \longrightarrow \text { clase de fruta }\end{array}$

Aquest mateix tractament es pot donar als casos de: "escudo", "tanque", "bases", "escuadras", "gatillos", "apuntar", "disparar", "bomba", "sirena", i "alarma". Entre aquestes paraules cal destacar els verbs ("apuntar" i "disparar"), el que demostra que aquestes relacions no són exclusives de noms i adjectius.

La segona part del treball podia estar centrada a analitzar les relacions de cada parella de significats. S'ha dit que quan un significant té més d'un significat es pot tractar d'un cas d'homonímia o de polisèmia. Caldrà veure si es comparteixen semes o no. El substantiu "espada" té el significat 'naipe', és evident, perquè a la carta es reprodueix el dibuix de l'arma; pot considerar-se fins i tot una metonímia, ja que la carta (el tot) pren el nom del dibuix (la part). Un cas semblant és el de la moneda, on ha quedat el nom d'una de les cares que hi és representada. I un fenomen diferent és el de "tanque", que en la seva accepció no bèl.lica es pot considerar una paraula de l'argot juvenil; però en aquest cas, ¿no tenen res a veure els dos significats? L'única possible relació és la grandària. El diccionari (R.A.E., 1989) ens pot treure de dubtes, perquè recull una accepció, dins l'entrada "tanque", que diu: "Ast., Rioja, Sant. y Vasc. Vasija pequeña con un asa para sacar un líquido contenido en otra vasija mayor". Això ens pot donar pistes: una accepció dialectal esdevé de l'argot juvenil, i el diccionari l'entén com a polisèmia (ja que apareix sota la mateixa entrada del 'carro de combat').

Crec que aquesta mostra serveix com a referència del treball que es pot fer en cada cas. Aqui només comentarem alguns casos més, que per alguna raó resultin especialment interessants. Aixi passa amb "gatillo", que sembla no tenir cap relació amb el felí, malgrat que el diccionari (R.A.E., 1992) diu que ve de "gato" i sota aquest lema incloeix tots els significats que pot tenir aquesta paraula; $a m b$ "sirena", cas en què costa, des de la sincronia, establir relacions entre aquells animals mitològics meitat peix, meitat dona (que originàriament no eren meitat peix, sinó au, per això cantaven tan bé ${ }^{11}$ ), i les sirenes que serveixen per avisar d'alguna cosa; perquè l'alumne (i el parlant mitjà) desconeixerà en molts casos els treballs dels Argonautes primer, i d'Ulisses després, per resistir llurs cants enfront de les costes de Sicília. I 

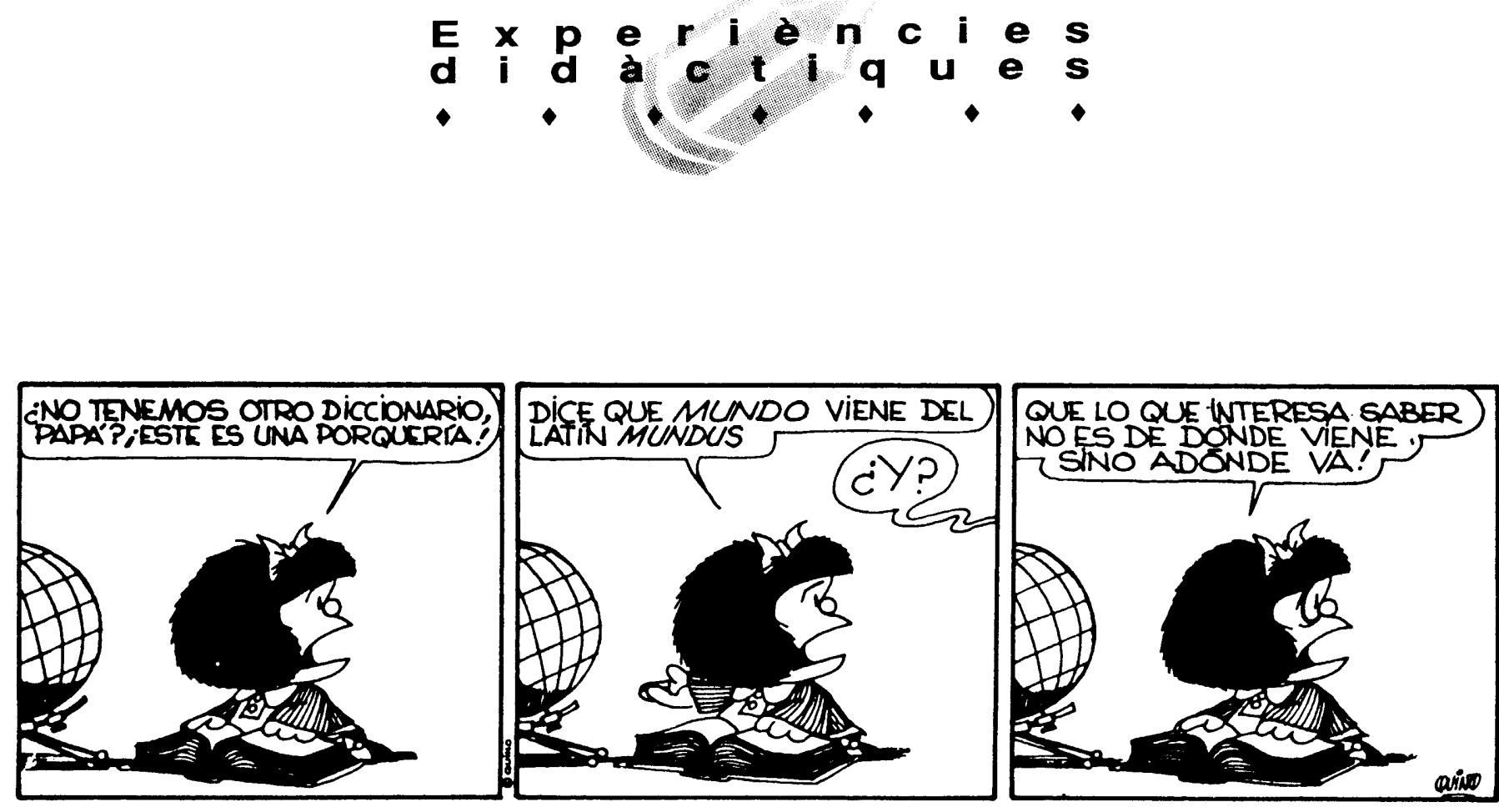

relacionat amb les sirenes, la "alarma", interessant per ella mateixa, com a formació lexicalitzada $i$ fins $i$ tot amalgamada de "al arma" (català "a l'arma"), que dóna lloc a derivacions: "alarmar", "alarmante», "alarmista», etc.

Per acabar aquesta part del comentari, una guinda. Quan esparla d'aquests fenòmens: homonimia, polisèmia, sinonímia, etc., sempre hi ha la fixació de centrar-se en el dialecte estàndar, i s'obliden, quan no es menyspreen, les altres varietats. Doncs aqui es troba exemplificat un cas d'homonímia produït per la neutralització dels fonemes líquids $/ \mathrm{V} \mathrm{i} / \mathrm{r} /$ en posició postnuclear (Navarro, 1957, 114): "alma» / "arma».

arma de vehi- anti- defen- tama- autoprofuego culo guo sivo no pulsado

$\begin{array}{llcccccc}\text { espada }+ & - & - & + & - & - & - \\ \text { tanque }+ & + & + & - & - & + & + \\ \text { escudo }+ & - & - & + & + & - & - \\ \text { persing }+ & + & - & - & - & + & + \\ \text { bomba }+ & + & - & - & - & + & - \\ \text { granada }+ & + & - & - & - & - & -\end{array}$

Per finalitzar amb aquestes propostes de treball centrades en l'àmbit semàntic, es podrien analitzar les relacions que les paraules de significat bèl.lic mantenen entre elles. Dit d'una altra manera, mirar de constituir un camp semàntic a partir de les unitats que s'han treballat, veient les oposicions $i$ associacions. Hi ha un grup de paraules que es presta a un tractament estructural: és el format per "espada", "tanque", "escudo", "bomba", "granada". S'hi pot afegir "persing", tot i que és el nom propi d'un determinat projectil:

Són evidents els problemes: "autopropulsado" pot ser un sema molt tècnic, però així consta al diccionari (R.A.E., 1989) ${ }^{12}$. Els lexemes "bomba" i "granada" són difícils de diferenciar, perquè el primer, en l'accepció més comuna, és hiperònim del segon, i fins i tot del lexema "persing". L'arxilexema seria "arma". I es poden trobar relacions molt evidents si s'analitzen els semes de "persing", "bomba" $i$ "granada", de "espada" $i$ "escudo", $i$ de "tanque" $i$ "persing". Ha de quedar palès que cada semema s'oposa, almenys en un sema, a tots els altres.

\section{Conclusió}

El treball didàctic del lèxic necessita un tractament científic que oblidi els sistemes rutinaris dels exercicis que donen frases per buscar sinónims o antònims, o que proposen l'alumne de formar families de paraules a partir d'un lexema donat, sense cap altra motivació. S'ha de tenir clar que la teoria ha de ser aprofitada per a la pràctica; aquí he mostrat algunes aplicacions de l'estructuralisme, en la línia dels treballs didàctics sobre el lèxic a França (Courtillon, 1989; Vigner, 1989). Estudiar metòdicament ellèxic, les relacions entre els mots, ajudarà a incorporar les noves paraules al vocabulari actiu i a delimitar amb claredat els contextos en què cada unitat pot aparèixer. Per això cal també conèixer els fonaments teòrics de la lingüistica, ja que ens donaran la possibilitat d'aprofitar molts recursos - com ara una cancó-, que formen part de la vivència de l'alumne i per tant resultaran més ben integrats.

${ }^{\dagger}$ Es pot consultar, en aquesta línia, el llibre de Cabré i Rigau (1985); en especial el capitol dedicat a la "Semàntica del mot" (pàgs. 161 a 175).

2 Per exemple Hjelmslev escriu: "Si existe un dominio en el que el escepticismo respecto al punto de vista estructural encuentra de nuevo su verdadero campo de aventura (...), es el del vocabulario" (Hjelmslev, 1972), ja que enfront de les unitats fòniques o gramaticals, que formen inventaris tancats, el lèxic és un inventari obert, il. limitat i inestable, amb creació i desaparició de paraules, etc. 


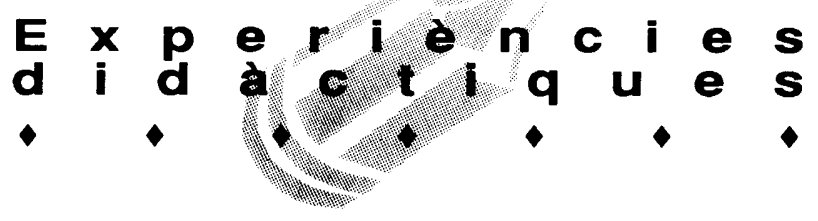

${ }^{3}$ A l'article: “Las solidaridades léxicas", (Coseriu, 1977,146). Perferun seguiment de l'evolució del concepte de camp lèxic en diversos autors, vegeu Quilis (1990, 467-483).

${ }^{4}$ Aixi ho expressa Jacqueline Picoche $(1977,10)$ : "Quels sont les rapports du signifiant et du signifié à l'intérieur d'un mot donné? Y a-t-il une différence entre polysémie et homonymie?".

${ }_{5}^{5}$ Per veure exemples en castellà, i seguir tot el raonament sobre la diferència entre polisèmia i homonímia, S. Gutiérrez (1989, 124-127).

${ }^{6}$ Per il.lustrar-ho, pot servir l'exemple que dóna Kurtz Baldinger del llatí "laudare" $i$ "locare", que en la seva evolució arriben al francès “louer ", amb els dos significats: lloar i llogar. Citat a Lamíquiz $(1987,220)$. S'hi poden trobar d'altres exemples d'aquest fenomen.

${ }^{7}$ Així ho expressa Lyons, $(1968,591)$ citant Ullmann: "E quasi una verità accertata che la sinonimia totale è un'occorrenza estremamente rara, un lusso che la lingua non si può permettere". Però no tots els autors són d'aquesta opinió. En un rotund article, l'acadèmic Gregorio Salvador $(1983,51-56)$ rebat tots els arguments que neguen l'existència de la sinonímia.

${ }^{8}$ Quilis i Hernández $(1990,496)$ ho exemplifiquen molt bé:»(...) 'libertino' se opone por un lado a 'casto' y por otro a 'religioso' o 'creyente'; 'libre' puede oponerse a 'prisionero', 'cautivo', 'esclavo', 'ocupado', 'molesto', 'embarazado', etc.

${ }^{9}$ Es pot trobar un bon estudi sobre els casos d'accepcions lexicogràfiques marcades com a figurades a Casares (1950, 102-162).

${ }^{10}$ Als diccionaris més antics del castellà, com ara el primer del'Academia (R.A.E., 1726) els sentits figurats apareixen marcats com a metafòrics.

11 "Las Sirenas son divinidades marinas (...) con cabeza y pecho de mujer y el resto del cuerpo de ave. (...) Dotadas de una maravillosa voz, osaron competir con las Musas, que las derrotaron y les arrancaron las plumas" (Falcón, 1980, 571). Diu el mite que després del pas d'Ulisses, avergonyides per la derrota, es van submergir.

12 Diu el diccionari (R.A.E., 1992): “misil o mísil: 'Proyectil autopropulsado, guiado electrónicamente".

\section{Referències bibliogràfiques}

BATTANER, M'P.; GUTIÉRREZ, J.; MIRALLES, E. (1985): Introducción a la enseñanza de la lengua y la literatura españolas. Madrid, Alhambra, 1989.

CABRÉ, M' T. I RIGAU, G. (1985): Lexicologia i semàntica. Barcelona, Enciclopèdia Catalana, 1987 (2' ed.).

CASARES, J. (1950): Introducción a la lexicografía moderna, Madrid, CSIC, 1969.

COROMINA, E. et alii. (1988): Marc referencial de programació; experimentació cicle 12-16. Desplegament curricular. Llengua i literatura. Barcelona, Generalitat de Catalunya (Departament d'Ensenyament).

COSERIU, E. (1977): Principios de semántica es tructural. Madrid, Gredos, 1981 (2' ed.).

COURTILLON, J.: "Lexique et apprentissage de la langue»; Lexique: recherches et applications, Français dans le monde, août-sept. 1989.

DEP. D'ENSENYAMENT (1990): Disseny curricular. Ensenyament Primari. Barcelona, Generalitat de Catalunya.

FALCóN, C. et alii (1980): Diccionario de la mitología clásica. Madrid, Alianza, 1986.

GóMEZ, G. (1989): El diseño curricular en la educación primaria. Madrid, Escuela Española.

GUTIÉRREZ, S. (1989): Introducción a La Semántica Funcional, Madrid, Síntesis.

HJELMSLEV, L. (1972): “Para una semántica estructural”, Ensayos lingüísticos, Madrid, Gredos.

NAVARRO, T. (1957): Manual de pronunciación española. Madrid, CSIC, 1989 (23' ed.).

LAMIQUIZ, V. (1987): Lengua española, método y estructuras lingüisticas. Barcelona, Ariel, 1989 (2' ed.).

LYONS, J. (1968): "La semantica", Introduzione alla linguistica teorica. Bari, Laterza, 1981.

LYONS, J. (1977): Semántica. Barcelona, Teide, 1982 (2'ed.).

PICOCHE, J. (1977): Précis de lexicologie française (l'étude et l'enseignement du vocabulaire), Millau, Nathan, 1983.

QUILIS, A.; i HERNáNDEZ, C. (1990): Lingüística española aplicada a la terapia del lenguaje, Madrid, Gredos.

R.A.E. (1726): Diccionario de Autoridades, Madrid, Gredos, 1984 (ed. facsímil).

R.A.E. (1992): Diccionario de la lengua española, Madrid, Espasa-Calpe (21'ed.).

R.A.E. (1989): Diccionario manual e ilustrado de la lengua española, Madrid, Espasa-Calpe (4' ed.).

SALVADOR, G. (1983): "Si hay sinónimos"; Semántica y lexicología del español. Madrid, Paraninfo, 1985.

SAUSSURE, F. (1916): Curso de lingüística general. Barcelona, Planeta-Agostini, 1985.

ULLMANN, S. (1965): Introducción a la semántica francesa, Madrid, Aguilar.

VIGNER, G.: "Thèmes, champs lexicaux et activités discursives»; Lexique:recherches et applications, Français dans le monde, août-sept. 1989. 